\title{
Environmental sustainability and pollution prevention
}

\author{
Boubaker Elleuch $^{1} \cdot$ Farah Bouhamed $^{1} \cdot$ Mabrouk Elloussaief $^{1} \cdot$ Madi Jaghbir $^{2}$
}

Received: 8 October 2017 / Accepted: 24 October 2017 / Published online: 10 July 2018

(C) Springer-Verlag GmbH Germany 2017

Environmental sustainability implies meeting our current needs without jeopardizing the right and the ability of future generations to meet theirs. Opportunities should be identified and taken to reduce the production of wastes and the use of toxic materials, to prevent soil, water, and air pollution and to conserve and reuse resources, as feasible. Environmental pollution with its health impacts is a key issue for sustainable environment (United Nations General Assembly 1987). Sustainability and sustainable development focuses on balancing that fine line between competing needs, our need to move forward technologically and economically, and the needs to protect the environments in which we and others live. Sustainability is not just about the environment (Kates et al. 2005); it's also about our health as a society in ensuring that no people or areas of life suffer as a result of environmental legislation, and it's also about examining the longer term effects of the actions humanity takes and asking questions about how it may be improved (World Commission on

Responsible editor: Philippe Garrigues

Farah Bouhamed

bouhamed.farah@gmail.com

Boubaker Elleuch

boubaker.elleuch@enis.rnu.tn

Mabrouk Elloussaief

eloussaiefmabrouk@yahoo.fr

Madi Jaghbir

jaghbirm@yahoo.com

1 Laboratory of Environmental Engineering and Ecotechnology (GEET) LR16ES19, National Engineering School, University of Sfax, P. Box 1173-3038, Sfax, Tunisia

2 Family and Public Health Department, The University of Jordan, Amman, Jordan
Environment and Development 1987). Sustainability has become a wide-ranging term that can be applied to almost every facet of life on Earth, from local to a global scale and over various time periods. Long-lived and healthy wetlands and forests are examples of sustainable biological systems. Invisible chemical cycles redistribute water, oxygen, nitrogen, and carbon through the world's living and non-living systems and have sustained life since the beginning of time. As the earth's human population has increased, natural ecosystems have declined and a change in the balance of natural cycles has had a negative impact on both humans and other living systems (Hawken 2007).

Pollution prevention reduces the amount of pollution generated by a process (industry, agriculture, or consumers). Pollution-control strategies, in general, seek to manage a pollutant after it is emitted and reduce its impact upon the environment; the pollution prevention approach, however, seeks to increase the efficiency of a process (Sherman et al. 2016), hence reducing the amount of pollution generated at its source. Although there is wide agreement that source reduction is the preferred strategy, some professionals also use the term pollution prevention to include pollution reduction.

With increasing human population, pollution has become a great concern. Pollution from human activities is a problem that does not have to be inevitable. With a comprehensive pollution prevention program, most pollution can be reduced, reused, or prevented. Reducing and managing pollution may decrease its health impacts (Thiel et al. 2015).

Pollution prevention however is a key issue to sustainability. Pollution results from waste. The best way to deal with pollution is to prevent it from being created in the first place. This means finding new efficiencies, doing things smarter, and valuing every resource. Understanding how waste is produced and how it can be minimized, or even prevented, is the first step to reduce waste and protect our environment; in that way, pollution prevention is an essential component of sustainability. 
Fundamental ideas of preventing pollution rather than fixing problems are essential for efficient, economically viable manufacturing, providing services, and addressing many environmental problems (Jorgenson and Wilcoxen 1990).

With new business tools, new materials, and new approaches, it is expected to innovate methods to reduce waste.

Prevention is the first priority within an environmental management hierarchy that includes prevention, recycling, treatment, and disposal or release. Pollution prevention, however, requires a cultural change, one which encourages more anticipation and internalizing of real environmental costs by those who may generate pollution (United States Environmental Protection Agency n.d.).

Our responsibility is to utilize our knowledge to take actions that are protective of human health and the environment.

All of the publications retained in this journal issue deal with methods and techniques suggested to maintain sustainable environment with its various components through pollution prevention and treatment. They were selected from the presentations in the International Conference in Integrated Management of Environment (ICIME) congress that has been conceived as a special platform to exchange knowledge among researchers from the Euro-Mediterranean region. The main idea was to share the different approaches to counteract the negative impacts of pollutants on the environment and human health: recent achievements of researchers acting within the region for remediation, protection, and smart management of pollution problems. It is the duty of the region scientist to find solutions for the negative impacts of pollutants resulting from our activities. The ICIME conference was held in Sousse, Tunisia, from 25 to 28 September 2016 to serve this purpose. More than 250 participants attended this event to share new findings and discuss the potential applications of such new processes that can be turned out to viable technique for sustainable development. A good and transparent work of selection has been undertaken to choose researches to inclusion in this special issue. The intense and fruitful exchange between the attending researchers showed their common concern to address the problem of waste and remediation together. Few problems may be specific to a given region, but similarity in the diagnosis as well as the remediation approaches demonstrated that the scientific community is in charge of bringing solutions for sustainable environmental protection. So, we are really grateful for researchers who attended this edition of ICIME; congratulations to the authors with published papers. We are thankful for all authors who actively contribute to the success of the meeting, hoping that there will be other occasions to meet and exchange ideas and new scientific findings. Doctor Philippe Garages, editor-inchief of the Environmental Sciences and Pollution Research, and the editorial team are acknowledged for their endless help during the review process of this special issue.

Special Issue is intended to improve our understanding of the current research and achievements in the broad field of sustainable environment and pollution prevention management. It includes, but is not limited to:

- Environmental assessment

- Soil, water, and air pollution

- Pollution prevention and treatment

- Assessment of pollution impact on the environment and on health

- Sustainable environment

\section{References}

Habicht FH (1992) EPA Definition of "Pollution Prevention" Memorandum. United States Environmental Protection Agency, Washington, DC

Hawken P (2007) Blessed unrest: how the largest movement in the world came into being and why no one saw it coming. Viking, New York, p 172

Jorgenson DW, Wilcoxen P (1990) Environmental regulation and U.S. economic growth. RAND J Econ 21(2):314-340

Kates R, Parris T, Leiserowitz A (2005) What is sustainable development? Goals, indicators, values, and practice. Environment 47(3): $8-21$

Sherman J, McGain F; FANZCA, FCICM (2016) Environmental sustainability in anesthesia pollution prevention and patient safety. 34:4761

Thiel CL, Eckelman M, Guido R et al (2015) Environmental impacts of surgical procedures: life cycle assessment of hysterectomy in the United States. Environ Sci Technol 49:1779-1786

United Nations General Assembly (March 20, 1987) "Report of the world commission on environment and development: our common future; Transmitted to the General Assembly as an Annex to document A/42/427 - Development and International Co-operation: Environment; Our Common Future, Chapter 2: Towards Sustainable Development; Paragraph 1". United Nations General Assembly

World Commission on Environment and Development (1987) Our common future. Oxford University Press, Oxford, p 27

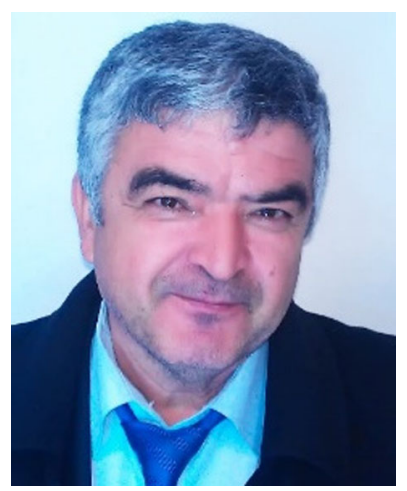

Boubaker Elleuch obtained his $\mathrm{PhD}$ at the University of Lyon, France. He published more than 60 international scientific papers and framed some 15 doctorates of young researchers. Pr Elleuch has been head of ENIS (1997-2003) and Head of ISET Sfax (20032009). Pr Elleuch organized several international scientific events and is an active funder of the research lab of Water, Energy and Environment. Full professor of Organic Chemistry and Environment in the Engineering School of Sfax. 


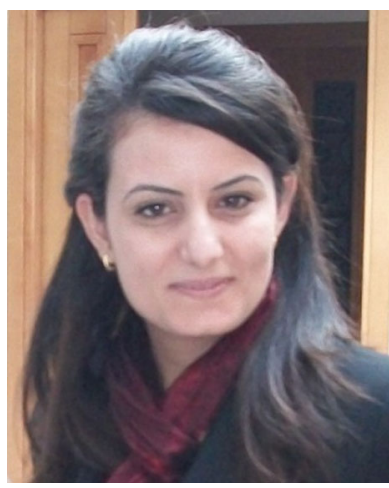

Farah Bouhamed is an assistant professor in the Faculty of Sciences of Gabes, University of Gabes, and a senior researcher at the National Engineering School of Sfax, Tunisia. She received her master's in Geosciences from the Faculty of Sciences, University of Sfax, Tunisia, and $\mathrm{PhD}$ under joint supervision "Geosciences, Ecology, Paleontology, Oceanography" at the University of Lille 1, France, and "Environmental Engineering and Land" National School of Sfax (ENIS), Tunisia. Her main research topic concerns the removal of hazardous metals from aqueous solutions by wastewater and phytoremediation of the contaminated soil. Currently, she is the executive member of the International Conference on Integrated Management and Environnent (ICIME), team member of the multilateral Project "ERANETMED" (assessing the chemical/microbiological contamination and productivity in the agricultural production chain of model fruit species grown under irrigation with different kinds of reclaimed wastewater), and assistant editor of the "Euro-Mediterranean Journal for Environmental Integration."

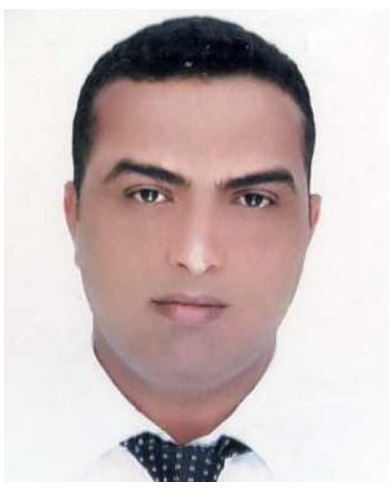

Mabrouk Elloussaief holds a $\mathrm{PhD}$ in Geo-materials and Environment from the University of Sfax, Tunisia. He is currently an assistant professor in the Department of Geology, Faculty of Sciences of Sfax, and he is loaded of the administrative and the logistic management of laboratory of Water, Energy and Environment (LR3E), localized in National School of Engineering of Sfax, Tunisia. His research focalizes on the use of geo-materials and their potential industrial and environmental applications. In specific, the activities of his research group include the identification, characterization of locally clay materials, and their application on the wastewaters treatment through several technical such as adsorption process. He has published over 12 papers in peer review international journals. He has organized and participated in many international conferences.

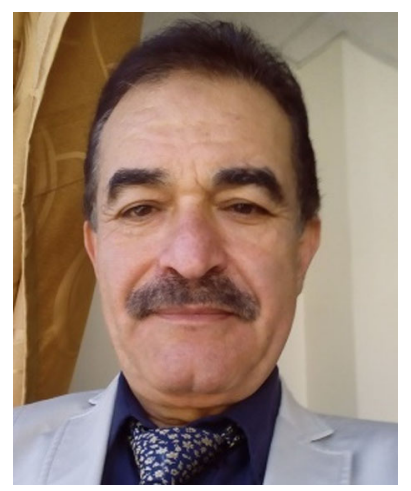

Madi Jaghbir is an MD graduated from The University of Jordan. He obtained his master's degree in Occupational Health and His D.Sc. (Environmental Health) from Tulane University, USA. $\mathrm{He}$ is the ex-dean (2010) and currently the head of Family and Public Health Department in The University of Jordan.He published more than 65 papers and books. He is a full professor of the Environmental and Occupational Health since 2002. 